\title{
Adherence to prescription-writing guidelines for outpatients in Southern Gauteng district hospitals
}

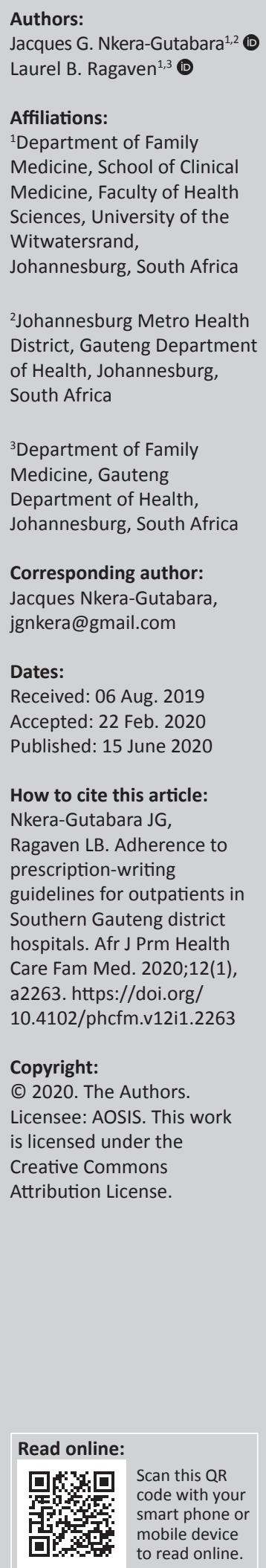

Background: Medical prescription writing is legally and professionally regulated in order to prevent errors that can result in patients being harmed. This study assesses prescriber adherence to such regulations in primary care settings.

Methods: A cross-sectional study of 412 prescriptions from four district hospital outpatient departments (OPDs) was conducted in March 2015. Primary outcome data were obtained by scoring prescriptions for accuracy across four categories: completion of essential elements, use of generic names of medications, use of recommended abbreviations and decimals and legibility. Secondary outcome data sought associations between accuracy scores and characteristics of the OPDs that might influence prescriber adherence.

Results: Completion of the essential elements, including patient identifiers, prescriber identifiers, treatment regimen and date scored $44 \%, 77 \%, 99 \%$ and $99 \%$ respectively. Legibility, the use of generic names of medications and the use of recommended abbreviations and decimals scored $90 \%, 39 \%$ and $35 \%$, respectively. Only 38\% of prescriptions achieved a global accuracy score (GAS) of between $80 \%$ and $100 \%$. A significant association was found between lower GAS and the number of prescriptions written per day $(p=0.001)$ as well as with the number of prescribers working on that day $(p=0.005)$, suggesting a negative impact on prescribers' performance because of workload pressures.

Conclusion: Low GAS values indicate poor adherence to prescription-writing regulations. Elements requiring substantial improvement include completion of patient and prescriber identifiers, use of generic medication names and the use of recommended abbreviations and decimals. This study provides baseline data for future initiatives for improvement in prescription-writing quality.

Keywords: medical prescription writing; prescribers; adherence to guidelines; scoring.

\section{Introduction}

Medical prescriptions are often the last encounters patients have with healthcare practitioners. Their writing is regulated by professional guidelines and the law. ${ }^{1,2,3}$ Prescription-related inaccuracies may impact negatively the quality of care and compromise patient safety, and they may lead to medication errors that have significant social, financial and legal consequences. $5,6,7,8$ Such errors can arise from errors related to medication prescribing, dispensing, administration or patient compliance; ${ }^{9,10}$ however, the origin of majority of errors noted in the medical prescription can be traced to writing by healthcare professionals, ${ }^{11}$ which can then have knock-on effects such as delayed dispensing. ${ }^{12}$ Prescription-writing errors account for up to $70 \%$ of medication errors that could potentially result in adverse effects. ${ }^{13}$

\section{Prescription-writing standards}

There have been international and domestic attempts at standard setting to determine the essential elements to be included when writing a prescription for medication. In South Africa, we are guided by the World Health Organization's (WHO) 'Guide to Good Prescribing', ${ }^{1}$ the National Department of Health's 'prescription writing' guidelines ${ }^{2}$ and, since 2017, the 'General Regulations' of the Medicines and Related Substances Act 101 of 1965 (Regulation 33), ${ }^{4}$ which were updated from the 2003 Regulation $28 .{ }^{3}$ While there is a great deal of overlap between these three sets of guidelines, they are however not all the same. The essential elements from these three different sources, which came into effect in 2015, are summarised and compared in Table 1, with the last column showing those that have been selected for this study. The justification for inclusion is explained in the footnotes of Table 1. 
TABLE 1: Comparative summary of elements essential to a medical prescription, according to international and domestic best practice.

\begin{tabular}{|c|c|c|c|c|}
\hline Medical prescription elements and their components & $\mathrm{WHO}^{1}$ & EML-2014 2 & $\begin{array}{l}\text { Medicines and Related Substances } \\
\text { Act } 101 \text { of } 1965 \text { (Regulation 28) }\end{array}$ & $\begin{array}{l}\text { Included for audit in this } \\
\text { study }\end{array}$ \\
\hline \multicolumn{5}{|l|}{ Elements and components } \\
\hline Date of prescription & + & + & + & + \\
\hline Names & + & + & + & + \\
\hline File number & & + & & + \\
\hline Address $\dagger$ & + & + & + & \\
\hline Sex & & & + & + \\
\hline Weight $† \dagger$ & & + & & + \\
\hline \multicolumn{5}{|l|}{ Treatment regimen } \\
\hline Medication name in full (either trade or generic) $+\uparrow \dagger$ & + & + & + & + \\
\hline Strength & + & + & + & + \\
\hline Dosage & + & + & + & + \\
\hline Frequency or interval & + & + & + & + \\
\hline Quantity§ & + & & + & \\
\hline Repeats & & + & + & + \\
\hline Use of medication generic name in full $\dagger \dagger \dagger$ & + & + & + & + \\
\hline Use of abbreviations and decimal points $\S \S$ & + & + & & + \\
\hline \multicolumn{5}{|l|}{ Prescriber identifiers } \\
\hline Name & + & + & + & + \\
\hline Address $\dagger$ & + & & + & \\
\hline Qualification or degree & & & + & + \\
\hline Professional registration number $\dagger$ & & & + & + \\
\hline Contact number $\dagger$ & + & + & & \\
\hline Signature & + & + & + & + \\
\hline Legibility of handwriting & & + & + & + \\
\hline Permanent copy $\uparrow)$ & & & + & \\
\hline Diagnosis |ף & & & + (with patient's consent) & \\
\hline Warnings\# & + & & & \\
\hline
\end{tabular}

OPD, outpatient department; WHO, World Health Organization; HPCSA, Health Professions Council of South Africa; MP, Medical Practitioner; EML, Essential Medicines List.

$\dagger$, The patient and prescriber addresses and the prescriber contact number, although legally required, were not included for assessment in this study, as all prescriptions were dispensed internally via the hospital OPD where both the patient and prescriber were situated. No outside prescriptions were considered. Similarly, practice number was replaced by the prescriber's professional registration number (e.g. HPCSA MP number) because all prescribers worked in the public sector.

$\dagger$, The patient's weight is mandatory for children, and it is also required for the frail elderly and where dosing is weight dependant; this allows for a double check by the dispenser.

$\dagger$, The medication name is scrutinised for full name use (not abbreviated) and separately for generic name use.

$\S$, Quantity of medication was left out as the dosage, frequency and treatment duration are its equivalent, and in most settings, the calculation of quantity of medication to dispense is a function of the pharmacy.

$\S \S$, Importantly, there are no legally approved abbreviations for medications. The WHO Guide to Good Prescribing ${ }^{1}$ and the Essential Medicines list ${ }^{2}$ caution

against the use of possibly confusing abbreviations because of the risk of misinterpretation. Similarly, decimal points should be employed only where they are unavoidable.

I, A permanent copy of the prescription is kept by the pharmacy.

9ף, The diagnosis is found in the patients notes to which the prescription is appended.

\#, Warnings are delivered verbally by pharmacist at the time of dispensing.

Despite the existence of these professional norms and legal standards, significant challenges related to adherence by prescribers are reported in international literature. ${ }^{11,12,13}$

Research on the reasons for poor quality of prescription writing deals with it from various perspectives, including the setting in which care is provided (from outpatient primary care to hospital wards and to specialised intensive care units) as well as the professional profiles of prescribers (amongst students in different professional programmes to consultants and university faculty). ${ }^{14,15,16,17}$ While generalising, there seems to be no single factor accounting for adherence or nonadherence to prescription-writing guidelines.

\section{Prescription-writing errors}

Indicators used to assess the accuracy of a medical prescription in compliance with writing regulations include the completion of essential elements, the use of generic names for medication, the use of recommended abbreviations and decimal points and, finally, script legibility if handwritten. The essential elements that must be completed are further broken down into 'the date of prescription', 'the patient identifiers', 'the treatment regimen' and 'the prescriber identifiers and signature'.

Errors of omission or incompleteness in prescription writing are the most reported ones. ${ }^{14,15,16,17,18,19,20,21,22,23,24,25,26,27,28}$ Other errors include the use of trade names of medications rather than their generic equivalents and the use of nonrecommended abbreviations and decimal points ${ }^{18,29,30}$ Handwritten prescriptions are consistently found to be more prone to errors than electronic ones. ${ }^{18}$ Junior doctors are reported to make more errors when prescribing medication, with insufficient knowledge and the work environment which includes heavy workload, time pressures and the influence of the prescribing habits of the seniors cited as contributing factors. ${ }^{19,20}$ Illegible handwritten scripts are also 
reported as a frequent cause of error. ${ }^{28,31,32}$ Legibility has been assessed using different methods including optical computer software and subjective scales, with the legibility of letter words (such as drug names) being worse than that of numbers (such as frequency of dosage). ${ }^{33,34,35}$ A validated tool, the Prescription Quality Index (PQI), provides indicators to measure legibility in chronic diseases using a three-point Likert scale, with scores of 0 for 'illegible', 1 for 'barely legible' and 2 for 'legible'. ${ }^{36}$

\section{Assessing and reporting on the quality of prescription writing}

The literature assesses and reports on the quality of prescription writing in various ways, including simple counts of present or missing elements of the prescription, graded scoring for the completion of elements (not completed, partially completed or fully completed) and classification of acceptability into categories according to scores realised. 36,37,38,39 Scaling and weighting have also been used in assessing the quality of a prescription; however, this is not required, nor is validation, for components that are purely descriptive in nature. $29,30,36,37,38,39,40,41$ Various aspects of quality assessment and reporting have been incorporated into this study.

\section{Prescription-writing quality improvement}

Improvement in the quality of medical prescription writing is achievable. Experience from other settings indicates, for example, that prescription audits in conjunction with education on rational pharmacotherapy improved the prescribing skills of fourth-year medical students. ${ }^{42}$ Serial audits and targeted interventions including educational strategies (such as feedback of audit results for prescribers on prescribing and medication errors) and changes in systems of practice (such as modifications to medication charts, publication of hospital-wide prescribing standards, an alert notification system and the implementation of electronic health records) have resulted in improvements for all of the indicators of medical prescription quality standards. ${ }^{21,43}$ A modified out-patient prescription chart with prompts for all the required elements to reduce prescription errors has been recommended, ${ }^{22}$ as were, in other studies, ongoing education programmes, follow-up reminders, regular audits and feedback sessions and the use of prescribers' self-inking stamps. ${ }^{16,17} \mathrm{~A}$ sevenfold decrease in prescription errors was reported with the introduction and adoption of electronic prescribing, ${ }^{44}$ which is consistent with 2008 systematic reviews on this subject. ${ }^{45,46}$

To our knowledge, there is no published study on adherence to South African regulations for medical prescription writing in primary care settings. An unpublished 2014 in-house audit of prescription writing in the outpatient department (OPD) of one district hospital in Southern Gauteng raised concerns, providing the impetus for this study, when it was found that $83 \%$ of 400 prescriptions had only achieved less than a $40 \%$ global accuracy score (GAS), with the remaining $17 \%$ of prescriptions scoring between $40 \%$ and $80 \%$, and $0 \%$ scoring between $80 \%$ and $100 \%$ in compliance with prescriptionwriting regulations. ${ }^{47}$
The purpose of this study therefore was to assess the adherence of prescribers across Southern Gauteng district hospitals to prescription-writing regulations and examine potential barriers in order to raise awareness and provide baseline data for future prescription-writing quality improvement initiatives.

\section{Methods Study design}

This is a cross-sectional study dealing with the accuracy in prescription writing with regard to adherence to regulations amongst all levels of prescribers (medical students, primary healthcare nurses, clinical associates, medical interns, medical officers and medical specialists) working in a primary care setting who were blinded to the study.

\section{Study site}

The study was conducted in the OPDs of four district hospitals in Southern Gauteng, representing the University of the Witwatersrand Family Medicine training platform.

\section{Study population}

The study included all medical prescriptions issued at the OPDs in Southern Gauteng district hospitals in March 2015, the day prior to the researcher's site visit.

\section{Sample size}

Considering the results of previous research that indicated the range of $1.3 \%-85.9 \%$ for accurately written prescriptions, with a precision of $5 \%$ and $95 \%$ confidence level at a power of $80 \%$, using Stata $12^{\circledR}$ (Stata Corp, College Station, TX, USA), the calculated sample size was 374 prescriptions.

\section{Sampling}

The selection of the hospitals to be surveyed was randomised as follows: one hospital was randomly selected from each of the three health districts with more than one district hospital; the fourth district hospital was in a district with only one such hospital. The names of the hospitals were written on A4 size papers that were folded four times, placed in a bucket and a researcher's colleague would pick one from the bucket for districts where there was more than one hospital. The order in which the hospitals were visited was from the furthest to those closest to the Wits University Medical School. A convenient sampling of a minimum of 100 consecutive OPD prescriptions written for adult and child patients and dispensed the previous day was assessed per hospital to ensure reaching the calculated sample size.

\section{Data collection instrument}

Nineteen essential elements of prescription writing were selected from existing regulations for this study (Table 1). These were compiled into a single data collection tool (Appendix 1), which was a Microsoft Excel ${ }^{\mathrm{TM}}$ spreadsheet, 
with variable codes and scoring. All data were manually extracted by the researcher (J.G.N.-G.) through a review of real prescriptions accessed from the pharmacies the day after all medications had been dispensed and kept in boxes by the pharmacist for this purpose.

\section{Variables}

For each prescription, the completion of the essential elements, the use of the generic names of medications, the use of recommended abbreviations and decimal points, and prescription legibility were evaluated, and an accuracy score out of 38 total points was determined. Each element was assessed, with scoring assigned as 0,1 or 2 for 'not completed', 'partially completed' or 'fully completed', respectively. The use of generic names of medications, recommended abbreviations and decimal points were scored 0,1 or 2 for 'not used', 'partially used' or 'fully used', respectively. The medicine name was scored twice, but for different aspects: firstly, for full and correct writing (not abbreviated) with either the trade or generic name in the treatment regimen; and, additionally, for the use of its recommended generic form.

Legibility was scored according to the $\mathrm{PQI}^{35}$ as 0,1 , or 2 for 'illegible', 'barely legible' or 'legible', respectively, as subjectively determined by the researcher.

Prescriptions for children were particularly checked for the completion of details regarding age and weight. Prescriptions for controlled substances were checked for full letter writing of dosages and quantities. In the South African context, this refers particularly to schedules 5 and 6 substances $^{1}$ which would be available in primary care facilities, and necessitate both medical diagnosis and management, and also enhanced control of supply. ${ }^{48}$

For prescriptions requiring two signatures (such as that of a medical student to be countersigned by a medical officer), the medical officer's signature will be used to determine the prescriber, unless there is no counter-signature, which would constitute a procedural omission. Prescriptions by community service doctors and registrars were counted as those given by medical officers as they could not be distinguished. Finally, other characteristics for each of the district hospital's OPD included the average number of OPD prescriptions per day and the number and professional categories of prescribers present in OPD on the day the prescriptions were written.

\section{Global accuracy score}

A GAS for each prescription was determined by calculating the total percentage achieved out of 38 possible points for the

1.Schedule 5 substances include psycho-active medicines such as sedatives and antidepressants (e.g. Benzodiazepines, Tramadol); they have a low to moderate potential for abuse or dependence. Schedule 6 substances are therapeutic narcotics and narcotic painkillers (e.g.Pethidine, Morphine, Tilidine); they have a moderate to and narcotic painkillers (e.g.Pethidine, Morphin
high potential for abuse or for dependence.
19 prescription elements considered (Table 1). Each GAS was then classified into one of the following four scores: 100\%, $80 \%-100 \%, 40 \%-79 \%$ and less than $40 \%$. The desired prescription-writing accuracy score, or gold standard, is $100 \%$; however, based on previous earlier findings, ${ }^{47}$ its expected rate was negligible.

Accuracy score category ranges of $80 \%-100 \%, 40 \%-79 \%$ and less than $40 \%$ were therefore used. These score ranges were purely descriptive, and are similar to the score ranges employed by the Council for Health Service Accreditation of Southern Africa (COHSASA) ${ }^{49}$ which is a private non-profit entity focussing on quality improvement and conducting healthcare facility accreditation.

\section{Outcome measures}

\section{Primary measures}

The completeness of essential elements of a prescription, the use of the generic names of medications, the use of abbreviations and decimal points, the legibility of the prescription, and a GAS for each prescription were determined.

\section{Secondary measures}

Calculated associations between the GAS categories with:

- the average number of OPD prescriptions per day

- the number of OPD prescribers on that day

- the prescribers' professional categories, grouped either as allied health professionals: categories $1-3$, or medical doctors: categories 4-6

- the type of prescription (adult, child and controlled substance).

\section{Data analysis}

After the electronic and direct entry onto the specially designed data collection tool in MS Excel, the data were cleaned, sorted and then exported into Stata $12^{\circledR}$ software for analysis. Descriptive analysis of the categorical data was conducted and results were presented in tables as frequencies and percentages as well as in figures. For elements with multiple components, the mean score and standard deviation (s.d.) were also determined. Cross-tabulation was used to explore possible associations between primary and secondary outcomes using statistical tests including the student's $T$-test, Pearson's Chi-squared test, Fisher's exact test and KuskralWallis test. A $p$-value of $<0.05$ was considered statistically significant. Logistic regression analysis was conducted where associations were found.

\section{Ethical consideration}

The approval to conduct this study was granted by the Human Research Ethics Committee (Medical) of the University of the Witwatersrand (clearance certificate number M141179). The CEOs of the four hospital issued authorisation letters granting permission to access their facilities for purposes of the study. A further undertaking 
form was signed with each hospital records administrator to not record and to preserve at all times the anonymity of patients and prescribers.

\section{Results}

A total of 412 prescriptions were analysed across all districts, with each of the hospital sites contributing approximately $25 \%$ of the entire sample. Table 2 is a descriptive account of the specific characteristics for each district hospital OPD as well as for the four district hospitals combined. Significant differences were found between the hospitals with regards to the average number of prescriptions per day, the number of prescribers on the day and the prescribers' professional category mix. The average number of prescriptions per day varied between 100 and over 300, and that of prescribers varied between six and eight on the days studied. Medical officers constituted $83.25 \%$ of the prescribers overall. Adult patients accounted for $96.12 \%$ of all prescriptions written.

Figure 1 illustrates the full completion in percentages of a prescription's 19 essential elements across the 412 prescriptions assessed in Gauteng South; the raw count and percentages showing fully completed, partially completed and not completed elements of the prescription for Gauteng South and for each of the four district hospitals are included as Appendix 3. It is worth noting that one

TABLE 2: Outpatient department site-specific characteristics per district hospital and for all of Southern Gauteng.

\begin{tabular}{|c|c|c|c|c|c|c|c|c|c|c|c|}
\hline \multirow[t]{3}{*}{ Variable } & \multicolumn{10}{|c|}{ Health district or district hospital sampled } & \multirow[t]{3}{*}{$p$} \\
\hline & \multicolumn{2}{|c|}{$\begin{array}{l}\text { COJ or } \\
\text { South Rand }\end{array}$} & \multicolumn{2}{|c|}{$\begin{array}{l}\text { West Rand or } \\
\text { Yusuf Dadoo }\end{array}$} & \multicolumn{2}{|c|}{$\begin{array}{l}\text { Ekurhuleni or } \\
\text { Bertha Gxowa }\end{array}$} & \multicolumn{2}{|c|}{$\begin{array}{l}\text { Sedibeng or } \\
\text { Kopanong }\end{array}$} & \multicolumn{2}{|c|}{$\begin{array}{c}\text { Southern Gauteng } \\
\text { total }\end{array}$} & \\
\hline & $\begin{array}{c}n \\
(101)\end{array}$ & $\begin{array}{c}\% \\
(24.51)\end{array}$ & $\begin{array}{c}n \\
(105)\end{array}$ & $\begin{array}{c}\% \\
(25.49)\end{array}$ & $\begin{array}{c}n \\
(105)\end{array}$ & $\begin{array}{c}\% \\
(25.49)\end{array}$ & $\begin{array}{c}n \\
(101)\end{array}$ & $\begin{array}{c}\% \\
(24.51)\end{array}$ & $\begin{array}{c}n \\
(412)\end{array}$ & $\begin{array}{c}\% \\
(100)\end{array}$ & \\
\hline \multicolumn{12}{|l|}{ Sites-specific characteristics } \\
\hline $\begin{array}{l}\text { Average number of OPD } \\
\text { prescriptions per day } \dagger\end{array}$ & $300+$ & - & $100-200$ & - & $201-300$ & - & $201-300$ & - & - & - & 0.001 \\
\hline $\begin{array}{l}\text { Number of OPD prescribers } \\
\text { present on the dayt† }\end{array}$ & 7 & - & 8 & - & 6 & - & 8 & - & - & - & 0.001 \\
\hline Type of prescriptions & & & & & & & & & & & 0.2 \\
\hline Adults & 96 & 95.04 & 102 & 97.14 & 100 & 95.23 & 98 & 97.02 & 396 & 96.12 & \\
\hline Paediatrics & 4 & 3.96 & 1 & 0.95 & 4 & 3.96 & 0 & 0.00 & 9 & 2.18 & \\
\hline Controlled substances & 1 & 0.99 & 2 & 1.90 & 1 & 0.95 & 3 & 2.97 & 7 & 1.70 & \\
\hline Prescriber categories & & & & & & & & & - & - & 0.001 \\
\hline 1. PHC nurses & 0 & 00 & 6 & 5.57 & 0 & 00 & 7 & 6.93 & 13 & 3.16 & \\
\hline 2. Medical students & 0 & 00 & 1 & 0.95 & 0 & 00 & 0 & 00 & 1 & 0.24 & \\
\hline 3. Clinical associates & 0 & 00 & 7 & 6.66 & 4 & 3.80 & 5 & 4.76 & 16 & 3.88 & \\
\hline 4. Medical interns & 19 & 18.81 & 4 & 3.80 & 0 & 00 & 10 & 9.52 & 33 & 8.01 & \\
\hline 5. Medical officers & 81 & 80.19 & 87 & 82.85 & 101 & 96.19 & 74 & 73.26 & 343 & 83.25 & \\
\hline 6. Specialists & 1 & 0.99 & 0 & 00 & 0 & 00 & 5 & 4.95 & 6 & 1.46 & \\
\hline
\end{tabular}

OPD, outpatient department; COJ, City of Johannesburg; PHC, Primary Health Care.

$\dagger$, Data for average number of OPD prescriptions were sourced from Pharmacy statistics.

$\dagger$, Data for number of OPD prescribers present on the day were sourced from OPD operational managers.

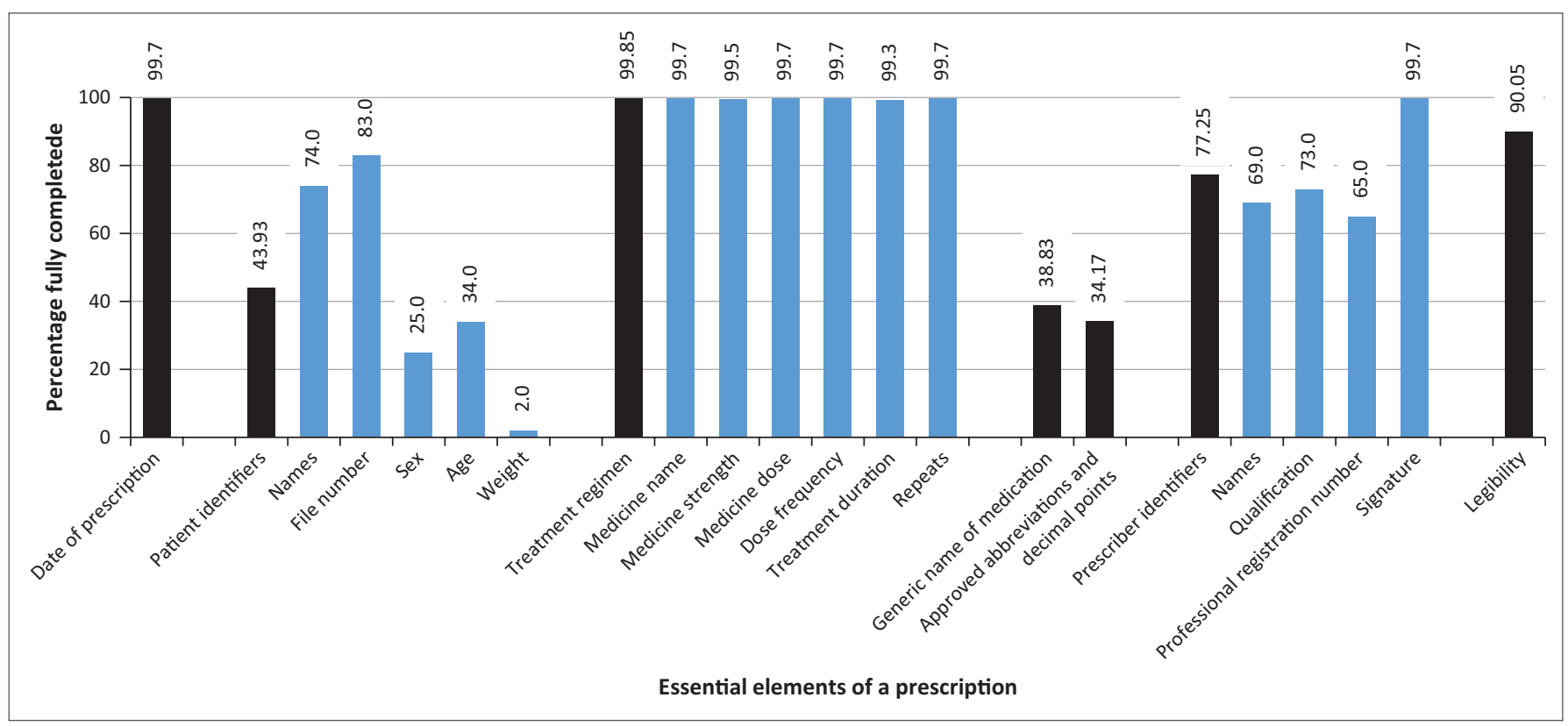

FIGURE 1: Scores for prescription completeness and accuracy across 19 essential elements for Southern Gauteng district hospitals $(N=412)$. 
prescription was signed for by a student and not countersigned by a medical officer, and existing internal memos allow clinical associates and medical interns to write OPD prescriptions, notwithstanding the challenge with regard to the legal status of clinical associates as authorised prescribers, as this category has not been accommodated in the schedules as required by the Medicines and Related Substances Act.

Prescribers achieved rates of $90 \%$ and over for completion of the date of the prescription, the treatment regimen, the prescriber's signature and handwriting legibility. The patient's file number was indicated in $83 \%$ of prescriptions. Lower rates were seen for the use of generic names of medications (39\%), abbreviations and decimal points (34\%) and for other components of patients and prescribers' identifiers. Particularly, low completion rates were seen for patients' sex (25\%), age (34\%) and weight (2\%).

Table 3 is a compilation of GASs: $37.52 \%$ of prescriptions scored $80 \%-100 \%$, whilst $62.38 \%$ scored $40 \%-79 \%$. The mean score out of 38 was $27.92(73.38 \%) \pm 5.53$ s.d.

TABLE 3: Global accuracy scores per prescription and by elements.

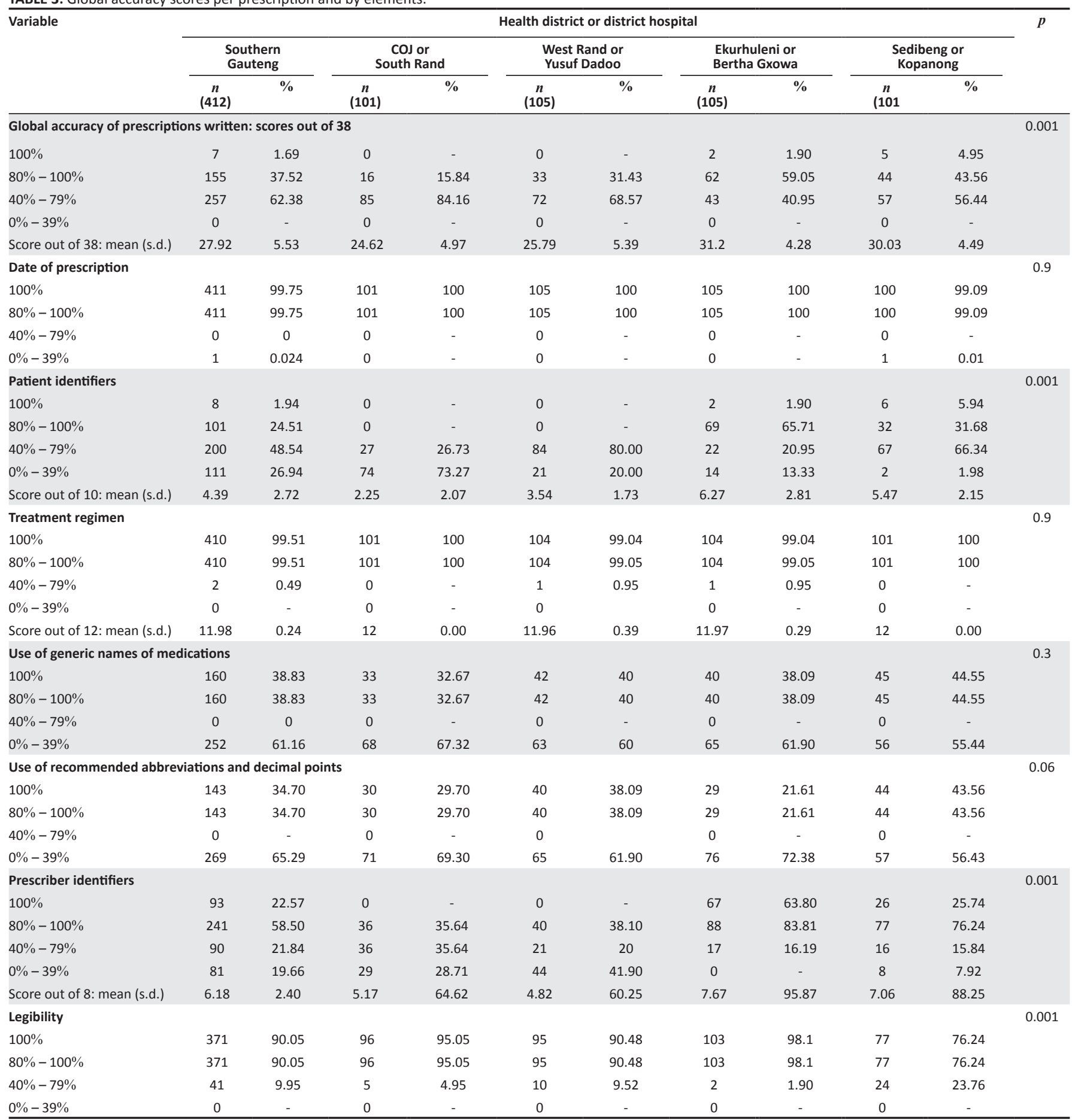

OPD, outpatient department; s.d., standard deviation. 
The inability to achieve a desired GAS of $\geq 80 \%$ was noted for the following elements: patient identifiers $(24.51 \%)$, the use of a medication's generic name $(38.83 \%)$. the use of recommended abbreviations and decimal points (34.70\%) and prescriber identifiers (58.50\%). High GAS values of $\geq$ $80 \%$ were noted for the following prescription elements: date of prescription (99.75\%), treatment regimen (99.51\%) and legibility (90.05).

The distribution of the GAS categories across the district hospitals in Southern Gauteng is indicated in Figure 2. Only in Ekurhuleni did more than half (59\%) of the audited prescriptions achieve a score of $80 \%-100 \%$.

We examined possible associations between specific characteristics of each OPD and prescription-writing GASs, which are summarised in Table 4. Significant negative associations were found between the ability to achieve a GAS of $80 \%-100 \%$ and the number of OPD prescriptions per day $(p=0.001)$ and the number of OPD prescribers on the day $(p=0.005)$. No associations were found between the prescription type or prescriber category and adherence to prescription-writing guidelines.

Seeking to understand the effects of the number of prescriptions written per day as well as of the variability in the number of providers on GAS values, we conducted

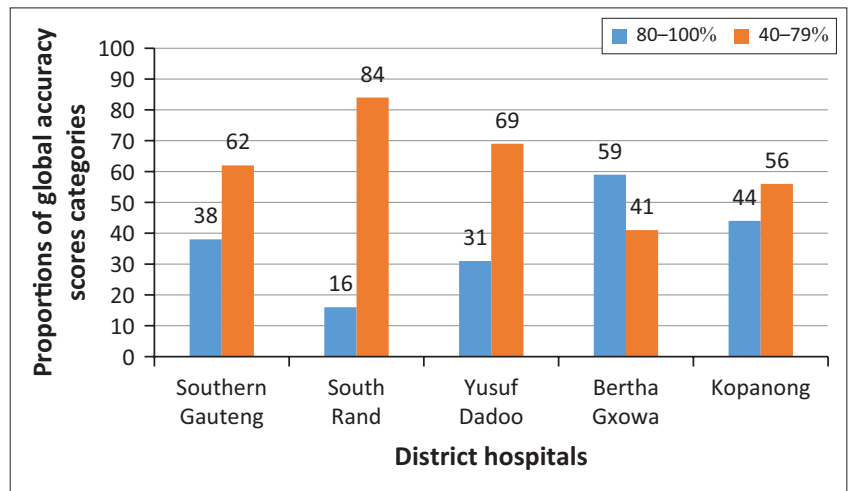

FIGURE 2: Distribution of global accuracy scores overall and per district hospital those achieving $80 \%-100 \%$ versus $40 \%-79 \%$. logistic regression analysis, which indicated that the number of OPD prescriptions per day and the number of OPD prescribers on the day were significant predictors of GAS values (Table 5).

Significantly, the hospital with more than 300 OPD prescriptions per day was $70 \%$ less likely to score $80 \%-100 \%$ compared to the hospital with 100-200 prescriptions per day (odds ratio [OR]: 0.30; 95\% CI: 0.14-0.62).

The relationship between the number of OPD prescribers (continuous variable) and GAS indicates that an increase in the number of prescribers on a day was associated with an odds ratio of 0.73 in the likelihood of scoring between $80 \%$ and $100 \%$ (OR: 0.73 ). In other words, with every increase in the number of prescribers, there is a reduced likelihood of scoring between $80 \%$ and $100 \%$, or reaching the target goal. Although this seems counterintuitive in light of the argument that high workload increases the likelihood of a reduced GAS, it suggests, using advanced statistics beyond the scope of this study, that it is possible to calculate optimal numbers of OPD prescriptions and OPD prescribers on any given day.

\section{Discussion}

To the best of our knowledge, this is the first effort in South Africa to develop a single tool that combines domestic regulatory and international best practice models to audit prescription-writing accuracy in the country's primary care settings. The results of this study provide a baseline understanding of challenges with prescribers' adherence to prescription-writing regulations. The results also suggest some possible reasons for omissions and inaccuracies in

TABLE 5: Logistic regression model for predicting global accuracy scores.

\begin{tabular}{lccc}
\hline Variable (characteristics) & Odds ratio & $\mathbf{9 5 \%} \mathrm{Cl}$ & $\boldsymbol{p}$ \\
\hline Number of OPD prescriptions per day & & & \\
$100-200$ & Ref & & \\
$201-300$ & 1.68 & $0.95-2.98$ & 0.073 \\
$300+$ & 0.30 & $0.14-0.62$ & 0.001 \\
Number of OPD prescribers per day & 0.73 & $0.55-0.96$ & 0.027 \\
\hline
\end{tabular}

OPD, outpatient department; $\mathrm{Cl}$, confidence interval.

TABLE 4: Associations between outpatient department-specific characteristics and prescription-writing global accuracy scores.

\begin{tabular}{|c|c|c|c|c|c|}
\hline \multirow[t]{2}{*}{ OPD characteristic } & \multicolumn{2}{|c|}{ Accuracy score $80 \%-100 \%$} & \multicolumn{2}{|c|}{ Accuracy score $40 \%-79 \%$} & \multirow[t]{2}{*}{ Test $\& p$-value } \\
\hline & $n(155)$ & $\%$ & $n(257)$ & $\%$ & \\
\hline \multicolumn{6}{|l|}{ Number of OPD prescriptions per day } \\
\hline $100-200$ & 33 & 31.43 & 72 & 68.57 & \multirow{3}{*}{$\begin{array}{c}\text { Pearson's Chi } \\
0.001\end{array}$} \\
\hline $201-300$ & 106 & 51.45 & 100 & 48.54 & \\
\hline $300+$ & 16 & 15.84 & 85 & 84.16 & \\
\hline Number of OPD prescribers on the day: mean (s.d.) & 7.10 & 0.08 & 7.33 & 0.05 & $\begin{array}{l}\text { Student's } T \\
0.005\end{array}$ \\
\hline \multicolumn{5}{|l|}{ Prescriber professional category } & \multirow{3}{*}{$\begin{array}{c}\text { Pearson's Chi } \\
0.107\end{array}$} \\
\hline Allied health professionals & 18 & 4.37 & 137 & 33.25 & \\
\hline Medical doctors & 45 & 10.92 & 212 & 51.46 & \\
\hline \multicolumn{5}{|l|}{ Prescription type } & \multirow{4}{*}{$\begin{array}{c}\text { Pearson's } \text { Chi }^{2} \\
0.480\end{array}$} \\
\hline Adult & 147 & 35.68 & 249 & 60.44 & \\
\hline Paediatric & 4 & 0.97 & 9 & 2.18 & \\
\hline Controlled substances & 3 & 0.73 & 4 & 0.97 & \\
\hline
\end{tabular}

OPD, outpatient department; s.d., standard deviation. 
prescription writing that could guide future quality improvement initiatives.

While sampling was restricted to four district hospitals' OPDs in Southern Gauteng, the required sample size for data collection was exceeded (374 intended; 412 actual), lending strength to the results. It was also apparent that not all the sites were in fact the same to start with, with statistically significant differences between the sites in relation to average number of OPD prescriptions per day, average number of providers and the professional category of prescribers (Table 2). These differences persisted in terms of GASs across the four sites, with interesting variations.

The composite GAS indicates that only seven (1.69\%) of the 412 prescriptions assessed achieved the desired $100 \%$ or gold standard, and only 155 prescriptions (37.52\%) scored 80\% $100 \%$. In Bertha Gxowa and Kopanong district hospitals, 59\% and $44 \%$ of the prescriptions achieved the GAS of $80 \%-$ $100 \%$,respectively, compared to $16 \%$ and $31 \%$ in South Rand and Yusuf Dadoo district hospitals, respectively. This is a significant difference (Kruskal-Wallis: $p=0.001$ ), largely attributed to the higher scores achieved for completion of patient and prescriber identifiers which, if not counted, would bring all the four district hospitals to similar lower GASs (Kruskal-Wallis: $p=0.9$ ).

Out of 38 total possible points, the mean score for all 412 prescriptions was $27.92(73.38 \%) \pm 5.53$ s.d. In Ife, Nigeria, Erhun et al. ${ }^{14}$ reported global percentages of $1.3 \%$ and $85.9 \%$ of completely filled medical prescriptions, respectively, from a health centre and a teaching hospital, and in France, Fourgon et al. ${ }^{25}$ reported $17 \%$ of fully accurate ambulatory patient prescriptions. Similar to our settings, most of these deficiencies pertained to omission errors.

The main omissions found in this study related to patient identifiers and prescriber identifiers in $56 \%$ and $23 \%$ of prescriptions, respectively. This may be explained by the practice of prescriptions being attached to the patient's file which already contains all of the patient's particulars, including the address, telephone contacts and medical diagnostic information. The prescriber in a busy OPD would rarely take the time to re-transcribe these details from the file to the prescription, and it seems this omission also occurs when it comes to write his or her own identifiers.

Practices reported in the literature to enable improved completion of these required identifiers include the consistent use of a sticker or label with the patient's details (with the birth date rather than the age) and the mandatory acquisition and consistent use of self-inking stamps with the required prescriber identifiers with only a signature required on the prescription. $^{23,24}$ These would be low-cost improvement measures as the sticker or label printing infrastructures already exist in the OPDs and self-inking stamps are not expensive.
High prescriber adherence to regulatory guidelines included completion of the treatment regimen (99\%). This is possibly because of the dispensers who, as the last gate keepers, created an institutional culture that places higher emphasis on the treatment regimen writing aspect of the prescription. This is in contrast to other settings where omissions of various components of the treatment regimen have been reported, with some even up to $91 \%$ incompleteness. ${ }^{31}$

Similarly, the date of the prescription was present $99 \%$ of the time; this was possibly because it is almost always stamped on the prescription chart by the clerk at the time of the patient's registration. In contrast, the date of prescription was omitted in up to $18 \%$ of prescriptions in the reported literature. ${ }^{26}$

Of note in this study is the fact that the generic names of medications were not used for $61 \%$ of prescriptions, and nonrecommended abbreviations and decimal points were used for $65 \%$ of prescriptions. Similarly, high proportions of poor compliance in this regard are reported in the literature. ${ }^{19,29}$ The Human Sciences Research Council in South Africa found in 2005 that amongst general practitioners only $11 \%$ prescribed by generic name and generic prescribing was below $50 \%$ in public facilities. ${ }^{50}$ Education and individual prescribers' efforts can improve on this at little cost. ${ }^{21}$

As has been evidenced elsewhere, the adoption of an electronic health record with electronic prescribing that includes standardised fields with prompts for certain patient conditions may result in greatly improved accuracy in all prescription-writing elements considered in this study. This may appear to be a high tech or high cost measure, but may be worth the investment given its positive impact on quality and reducing medication error, ${ }^{44,45,46}$ especially in our environment with increasing malpractice and adverse event litigation.

Significant differences were noted between the district hospitals for GAS values and the essential elements of patient identifiers, prescriber identifiers and legibility. Although no association was found between the prescription type (noting the small numbers of paediatric and controlled substances prescriptions) and the prescriber's professional category, performance differences have been reported between prescriber categories in the literature. ${ }^{16,17,18,19}$ This also could have happened because not all categories of prescribers were present in the OPD on the day prior to data collection. Therefore, other prescribers at that facility would have been missed and potential differences never examined. Similarly, the significant difference in legibility scores may have been caused by one prescriber in a particular district hospital on that day.

The negative associations found between GASs and the number of OPD prescriptions and prescribers per day are suggestive of a negative impact of a heavy workload on the accuracy in prescription-writing, as also reported by 
Ajemigbitse et al. in Nigeria. ${ }^{19}$ As suggested by the logistic regression model for predicting GAS values in Table 5, it is possible to determine an optimal number of prescriptions and prescribers per day to minimise inaccuracies, and performance may be even further enhanced if e-prescribing or a computerised physician order entry (CPOE) system could be introduced, ${ }^{44,45,46}$ notwithstanding its high cost, especially given that handwritten prescriptions are consistently found to be more prone to errors than electronic ones. ${ }^{18}$ In limited resource settings, however, prescriptionwriting quality improvement may still be achieved by using simple low-cost methods such as regular audits and feedback sessions, and the use of prescribers' self-inking stamps as highlighted above. ${ }^{16,17}$

Several limitations may restrict the generalisability of this study. The lack of diversity in prescription types was discovered only after data collection. It seems that paediatric medical records were kept in separate paediatric clinics within the OPDs and that 'controlled substances' records were also usually separated from other records for the purposes of oversight; moreover, as these same categories of patients attended OPD on particular days, their prescriptions may have been missed in the survey. An important additional type of prescription would be that of the elderly, which we did not examine specifically. Importantly, the 'correctness' of the medication as it correlated with the medical condition being treated and adherence to treatment guidelines by prescribers in their choice of medication were not assessed. Nor were prescriptions differentiated between new and repeats, or scripts for single versus multiple drugs. Also the snapshot or 1-day survey may have reduced the variability amongst the prescribers; and, to understand the impact of the numbers of patients and prescribers, the sampling mechanism could be refined. Inclusion of these aspects may enhance the results of a future study.

A combination of legal requirements and professional guidelines, drawn from local and international sources, was used in selecting variables in this study (Table 1). The legally binding requirements were drawn from the law in application at the time of data collection ${ }^{3}$ and included amongst the prescriber's identifiers the 'practice number'. However, 'professional registration number' was used as it was required as a best practice although it was not the legal requirement then. The General Regulations to the Medicines and Related Substances Act issued in $2017^{50}$ replacing the one of $2003^{3}$ modified the legal requirement to be included in the prescriber's identifiers from the 'practice number' to 'registration number with the relevant statutory health council', that is, the 'professional number' which identifies the individual prescriber better. The 'practice number' is not used for in-house district hospital OPD prescriptions. Its use as a variable might have had some impact on the results obtained, but not on the associations observed.

The $90 \%$ legibility score observed in this study is at odds with the literature where much higher proportions of illegible scripts are reported. ${ }^{16,17,18,19}$ Also in the assessment of legibility, all the scoring was done by the same person, the researcher alone. His familiarity with the OPD medicines and the environments could introduce a researcher bias. However, on-site pharmacists anecdotally reported difficulty reading only less than one in 10 scripts.

\section{Conclusion and recommendations}

This study revealed that in Southern Gauteng district hospitals, of 412 OPD medical prescriptions surveyed, onethird achieved a GAS of $80 \%-100 \%$, with two-thirds scoring between $40 \%$ and $79 \%$ for compliance with prescriptionwriting regulations. The most common deficiencies relate to the omission of patient and prescriber identifiers, with completion rates of $43.93 \%$ and $77.25 \%$, respectively. Also, medication generic names and recommended abbreviations and decimal points were used in only $38.83 \%$ and $34.17 \%$ of prescriptions, respectively. Associations were found between accuracy scores and the number of OPD prescriptions per day $(p=0.001)$ and the number of OPD prescribers on the day $(p=0.005)$, pointing to a negative impact of high patient volumes and multiple providers on reducing the accuracy of prescription writing.

A prescription-writing quality improvement programme would be an appropriate framework to implement recommendations pertaining to institutions or systems and individual prescribers. These recommendations include low-cost or low-tech measures, such as the consistent availing and use of pre-printed stickers with the patient's particulars on prescriptions and the mandatory use of selfinking stamps with the required particulars for prescribers. Reinforcement is also required regarding the consistent use of generic names of medications and being vigilant about the use of abbreviations and decimal points. E-prescribing, although a high-cost endeavour for our limited resources settings, may be considered given its positive impact elsewhere on the quality of prescription writing and medication error reduction.

\section{Acknowledgements}

The authors are grateful to Prof. Laurel Baldwin-Ragaven for giving adequate attention to all aspects of the research. The authors are also thankful to Dr Zuberu Elabor for his help in the initial phase of protocol development and to Mrs D Pretorius, Dr Jimmy Akii and the Johannesburg Health District Family Physicians for providing facilities and support. The CEOs and Pharmacists of South Rand, Bertha Gxowa, Yusuf Dadoo and Kopanong district hospitals deserve special thanks for providing the permission to access their medical records. Special thanks are extended to the biostatisticians from the Wits School of Public Health for providing assistance with statistical analysis, particularly $\mathrm{Mr}$ E Ngamasana, Mr L Nyathi and Dr G Olorunfemi. Claudine Kanyana is also acknowledged for the invaluable logistics support provided by her. 


\section{Competing interests}

The authors have declared that no competing interests exist.

\section{Authors' contributions}

Dr J.G. N.-G. was the principal investigator and helped in protocol development, data collection, analysis and writeup. Prof. L.B.-R. was responsible for academic supervision; a detailed critical review of the write-up with substantial editing; and conceptual, analytical and intellectual input at all stages.

\section{Funding information}

This research received no specific grant from any funding agency in the public, commercial or not-for-profit sectors.

\section{Data availability statement}

Anonymised data can be requested from the corresponding author when access has been permitted given that the necessary and appropriate ethical and legal data sharing agreements are in place.

\section{Disclaimer}

The views and opinions expressed in this article are those of the authors and do not necessarily reflect the official policy or position of any affiliated agency of the authors.

\section{References}

1. De Vries $T$, Henning $R$, Hogerzeil $H$, Fresle $D$, Haaijer-Ruskamp $F$, Van Gilst $R$. Guide to good prescribing: A practical manual [homepage on the Internet]. Vol. 94, No. 11. Geneva: World Health Organization Action Programme on Essential Drugs 1994 [cited 2016 Mar 22]; p. 66-70. Available from: http:www.who.int/iris/ handle/10665/59001

2. Republic of South Africa. Essential Drugs Programme. Primary healthcare standard treatment guidelines and essential medicines list [homepage on the Internet]. 5th ed. National Department of Health, 2014 [cited 2017 Nov 12]; p. xxi-xxii. Available from: apps.who.int/medicinedocs/documents/s23015en/s23015en.pdf

3. South African Government. General regulations made in terms of the Medicines and Related Substances Act 101 of 1965, as amended-Government Notice R510 in Government Gazette No. 24727 dated 10 April 2003 (Regulation 28). 2013.

4. South African Government. General regulations made in terms of the Medicines and Related Substances Act 101 of 1965, as amended-Government Notice No. 859 in Government Gazette No. 41064, dated 25 August 2017 (Regulation 33). 2017.

5. Phillips DP, Christenfeld N, Glynn LM. Increase in US medication-error death between 1983 and 1993. Lancet. 1998;351(9103):643-644. https://doi. org/10.1016/S0140-6736(98)24009-8

6. Kohn LT, Corrigan JM, Donaldson MS. To err is human: Building a safer health care system. Report of the Institute of Medicine (US) Committee on Quality Health Care in America. Washington, DC: National Academies Press (US); 2000. https:// doi.org/10.17226/9728

7. Audit Commission. A spoonful of sugar- medicines management in NHS hospitals [homepage on the Internet]. London: Audit Commission; 2001 [cited 2017 Nov 12]. Available from: www.eprescribingtoolkit.com/wp-content/uploads/2013/11/ nrspoonfulsugar1.pdf

8. Department of Health. An organisation with a memory [homepage on the Internet]. Report of an Expert Group on Learning from Adverse Events in the NHS Chaired by the Chief Medical Officer. London: The Stationery Office; 2000 [cited 2017 Nov 12]. Available from: https://www.aagbi.org/sites/.../files/ Anorganisationwithamemory.pdf

9. American Society of Hospital Pharmacists. ASHP guidelines on preventing medication errors in hospitals. Am J Health Syst Pharm [serial online]. 1993 [cited 2017 Nov 12];50:305-314. Available from: https://www.ashp.org/PharmacyPractice/...Guidelines/.../Medication-Misadventures

10. Miller MR, Clark JS, Lehmann CU. Computer based medication error reporting: Insights and implications. Qual Saf Health Care. 2006;15:208-213. https://doi. org/10.1136/qshc.2005.016733
11. Dean B, Schachter M, Vincent C, et al. Prescribing errors in hospital inpatients: Their incidence and clinical significance. Qual Saf Health Care. 2002;11(4):340344. https://doi.org/10.1136/qhc.11.4.340

12. Hansen LB, Fernald D, Araya-Guerra R, et al. Pharmacy clarification of prescriptions ordered in primary care: A report from the applied strategies for improving patient safety (ASIPS) collaborative. J Am Board Fam Med 2006;19:24-30. https:// doi.org/10.3122/jabfm.19.1.24

13. Velo G, Minuz P. Medication errors: Prescribing faults and prescription errors. Br J Clin Pharmacol. 2009;67(6):624-628. https://doi.org/10.1111/j.13652125.2009.03425.x

14. Erhun WO, Adekoyab OA, Erhun MO, et al. Legal issues in prescription writing: $A$ study of two health institutions in Nigeria. Int J Pharm Pract. 2009;17:189-193. https://doi.org/10.1211/ijpp.17.03.0010

15. Tayem $\mathrm{YI}$, Ibrahim MA, Qubaja MM, et al. Compliance with the guidelines of prescription writing in a central hospital in the West Bank. East Mediter Health J [serial online]. 2013 [cited 2017 Jun 19];19(9):802-806. Available from: https:// search. proquest.com/docview/1467532643?pq-origsite=gscholar

16. Al Khaja KA, Al-Ansari TM, Sequeira RP. An evaluation of prescribing errors in primary care in Bahrain. Int J Clin Pharmacol Ther. 2005;43(6):294-301. https:// doi.org/10.5414/CPP43294

17. Walson PD, Hammel M, Martin R. Prescription-writing by pediatric house officers. J Med Educ [serial online]. 1981 [cited 2017 Sept 09];56(5):423-428. Available from: http://pdfs.journals.Iww.com/academicmedicine/1981/05000/ Prescription_writing_by_pediatric house_officers.7.pdf

18. Marwaha $M$, Kumar R, Marwaha $U$, et al. A retrospective analysis on a survey of hand written prescription errors in general practice. Int J Pharm Sci [serial online] 2010 [cited 2017 Sept 09];2(2):80-82. Available from: www.ijppsjournal.com/ Vol2Suppl3/613.pdf

19. Ajemigbitse AA, Kayode M, Omole MK, et al. Assessment of the knowledge and attitudes of intern doctors to medication prescribing errors in a Nigeria Tertiary Hospital. J Basic Clin Pharm. 2014;5(1):7-14. https://doi.org/10.4103/09760105.128244

20. Ross S, Ryan C, Duncan EM, et al. Perceived causes of prescribing errors by junior doctors in hospital inpatients: A study from the PROTECT programme. BMJ Qual Saf. 2013;22(2):97-102. https://doi.org/10.1136/bmjqs-2012-001175

21. Gommans J, McIntosh P, Bee S, Allan W. Improving the quality of written prescriptions in a general hospital: The influence of 10 years of serial audits and targeted interventions. Intern Med J. 2008;38(4):243-248. https://doi org/10.1111/j.1445-5994.2007.01518.x

22. Kennedy AG, Littenberg B. A modified outpatient prescription form to reduce prescription errors. Joint Commission J Qual Patient Saf. 2004;30(9):480-487. https://doi.org/10.1016/S1549-3741(04)30056-0

23. Meyer TA. Improving the quality of the order-writing process for inpatient orders and outpatient prescriptions. Am J Health Syst Pharm. 2000;57(4):18-22. https:// doi.org/10.1.1.618.1469

24. Glisson JK, Morton ME, Bond AH, et al. Does an education intervention improve physician signature legibility? Pilot study of a prospective chart review. Perspect Health Inf Manag [serial online]. 2011 [2017 September 09];8:1e. Available from: https://www.ncbi.nlm.nih.gov/pubmed/21796267

25. Fourgon R, Vicrey C, Blanchon B, et al. The editorial quality of hospital drug prescriptions in the lle de France area. A study by the Health Insurance. Presse Med [serial online]. 2005 [cited 2017 Jul 12];34(3):203-207. Available from: https://www.ncbi.nlm.nih.gov/pubmed/15798530

26. Al Shahaibi NM, Al Said LS, Kini T, et al. Identifying errors in handwritten outpatient prescriptions in Oman. J Young Pharm. 2012;4(4):267-272. https:// doi.org/10.4103/0975-1483.104371

27. Desta Z, Abdulwhab M. Prescription writing in Gondar outpatient teaching hospital, Ethiopia. East Afr Med J [serial online]. 1996 [cited 2017 Mar 29];73(2):115-119. Available from: https://www.researchgate.net/publication/14446716_Prescription_ writing_in_Gondar_outpatient_teaching_hospital_Ethiopia

28. Makonnen E, Yoseph M, Berhane Y. Quality of prescription at a tertiary care pharmacy in Addis Ababa. Ethiop Med J [serial online]. 2002 [cited 2017 Mar 29];40(3):233-239. Available from: https://www.ncbi.nlm.nih.gov/m/ pubmed/12602247

29. Afify MA, Shahzad N, Tawfik N, et al. Evaluation of drug prescribing practices in private and general hospitals in Makkah, Saudi Arabia. Afr J Pharm Pharmacol. 2015;9(39):966-973. https://doi.org/10.5897/AJPP2015.4320

30. Relihan E, Harbison J, Silke B, et al. Audit and feedback to improve the quality of prescription writing. Int J Clin Pharm. 2012;34(1):256. https://doi.org/10.1007/ s11096-011-9602-2

31. Irshaid YM, Al Homrany M, Hamdi AA, et al. Compliance with good practice in prescription writing at outpatient clinics in Saudi Arabia. Rev Santé Méd Orient [serial online]. 2005 [cited 2017 Mar 29]:11(5):922-928. https://www.ncbi.nlm. nih.gov/pubmed/16761662

2. Kaushal R, Goldmann DA, Keohane CA, et al. Medication errors in paediatric outpatients. Qual Saf Health Care. 2010;19(6):30. https://doi.org/10.1136/ qshc.2008.031179

33. Lyons R, Payne C, McCabe M, Fielder C. Legibility of doctors' handwriting Quantitative comparative study. BMJ. 1998:317(7162):863-864. https://doi. org/10.1136/bmj.317.7162.863

34. Dharmadikari SD, Jaju JB, Pawar GR, et al. Retrospective analysis of completeness and legibility of prescription orders at a tertiary care hospital. Natl J Physiol Pharm Pharmacol. 2014;4:165-167. https://doi.org/10.5455/ njppp.2014.4.011020131 
35. Albarrak Al, Al Rashidi EA, Fatani RK, et al. Assessment of legibility and completeness of handwritten and electronic prescriptions. Saudi Pharm J. 2014;22(6):522-527. https://doi.org/10.1016/j.jsps.2014.02.013

36. Hassan NB, Ismail HC, Naing L, et al. Development and validation of new prescription quality index. Br J Clin Pharmacol. 2010;70(4):500-513. https:// doi.org/10.1111/j.1365-2125.2009.03597.x

37. Chaturvedi SK, Sinha P, Chandra PS, et al. Improving quality of prescriptions with clinical audit. Ind J Med Sci. 2008;62(11):461-464. https://doi.org/10.4103/00195359.48460

38. Solanki ND, Shah C. Prescription audit in outpatient department of multispecialty hospital in western India: An observational study. Int J Clin Trials. 2015;2(1):1419. https://doi.org/10.5455/2349-3259.ijct20150203

39. Alagoa PJ, Mukoro DG, Yeibake WS. Audit of prescription notes from a tertiary health centre. IOSR J Dent Med Sci. 2014;13(1):79-82. https://doi.org/10.9790/085313127982

40. Dyasanoor S, Urooge A. Insight into quality of prescription writing - An institutional study. J Clin Diagn Res. 2016;10(3):61-64. https://doi.org/10.7860/ JCDR/2016/18011.7472

41. Oborne CA, Batty GM, Maskrey V, et al. Development of prescribing indicators for elderly medical inpatients. Br J Clin Pharmacol. 1997;43:91-97. https://doi. org/10.1111/j.1365-2125.1997.tb00143.x

42. Akici A, Gören MZ, Aypak C, et al. Prescription audit adjunct to rational pharmacotherapy education improves prescribing skills of medical students. Eur Clin Pharmacol. 2005:61(9):643-650. https://doi.org/10.1007/s00228-005-0960-3

43. Ostini R, Hegney D, Jackson C, et al. Systematic review of interventions to improve prescribing. Ann Pharmacother. 2009;43(3):502-513. https://doi.org/10.1345/ aph.1L488
44. Kaushal R, Kern LM, Barrón Y, Quaresimo J, Abramson EL. Electronic prescribing improves medication safety in community-based office practices. J Gen Intern Med. 2010;25(6):530-536. https://doi.org/10.1007/s11606-009-1238-8

45. Eslami S, De Keizer NF, Abu-Hanna A. The impact of computerized physician medication order entry in hospitalized patients - A systematic review. Int J Med Inform. 2008;77(6):365-376. https://doi.org/10.1016/j.ijmedinf.2007.10.001

46. Ammenwerth $E$, Schnell-Inderst $P$, Machan C, Siebert U. The effect of electronic prescribing on medication errors and adverse drug events: A systematic review. Am Med Inform Assoc. 2008;15(5):585-600. https://doi.org/10.1197/jamia. M2667

47. Nkera JG. Audit of medical prescriptions writing compliance with essential medicines list standards in the outpatient Department of South Rand Hospital, Johannesburg: A quality improvement project. Johannesburg: Department of Family Medicine, University of the Witwatersrand; 2013 (Unpublished report).

48. Republic of South Africa, Medicines Control Council, Scheduling of Medicines. Guidelines for the Scheduling Committee of the Medicines Control Council [homepage on the Internet]. National Department of Health; 2014 [cited 2018 Jun 08]. Available from: www.mccza.com/documents/a56714ff2.36_Scheduling_ of_Medicines_Jun14_v1

49. The Council for Health Service Accreditation for Southern Africa. Healthcare standards development, Southern Africa/Cohsasa [homepage on the Internet] 2015 [cited 2015 Aug 19]. Available from: www.cohsasa.co.za/health-carestandards-development

50. Peltzer K, Phaswana-Mafuya N, Mohlala G, et al. Impact of the national drug policy on pharmaceuticals in two provinces in South Africa [homepage on the Internet]. Pretoria: Human Sciences Research Council (HSRC); 2006 [cited 2020 Feb 06]. Available from: $h t t p: / / h d l . h a n d l e . n e t / 20.500 .11910 / 6500$ 